16 a 18 de outubro de 2019 - Campinas | Brasil

\title{
Análise de estabilidade de Lyapunov em sistemas positivos.
}

\section{Leonardo Felipe Toso*,Professor Dr.Matheus Souza.}

\section{Resumo}

$\mathrm{Na}$ vasta teoria de controle é relevante a análise da estabilidade de um sistema em torno de seus pontos de equilíbrio. Para tanto utilizam-se diversos critérios para estabelecer se o sistema é estável ou não.Neste presente trabalho as definições de estabilidade que serão utilizadas são as de Lyapunov. Para ilustrarmos esta análise,nosso foco neste trabalho é o estudo de estabilidade de sistemas positivos.

\section{Palavras-chave:}

Estabilidade,Lyapunov, Sistemas Positivos.

\section{Introdução}

Os sistemas positivos modelam dinâmicas que envolvem apenas variáveis de estado, entradas e saídas não-negativas. Suas aplicações vão desde sistemas econômicos até dinâmica de populações.

O objetivo desse projeto é apresentar a estabilidade desse sistema em um ponto próximo a origem, através da desigualdade de Lyapunov.

\section{Resultados e Discussão}

Através dos conceitos associados a estabilidade de Lyapunov, foi possível analisar a estabilidade do sistema para um conjunto de valores iniciais para a entrada do sistema, quando o mesmo é definido por uma função linear co-positiva, função máximo e função quadrática. Todas estas funções são equivalentes para sistemas positivos.

O teste para a resolução da desigualdade de Lyapunov de um sistema positivo foi feito no CVX e as simulações mostradas nas figuras a seguir foram feitas no MATLAB.

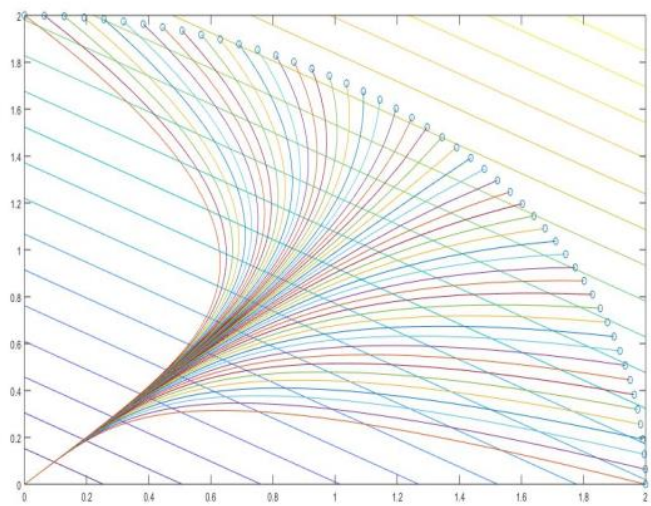

Figura 1. Função Linear Co-positiva.

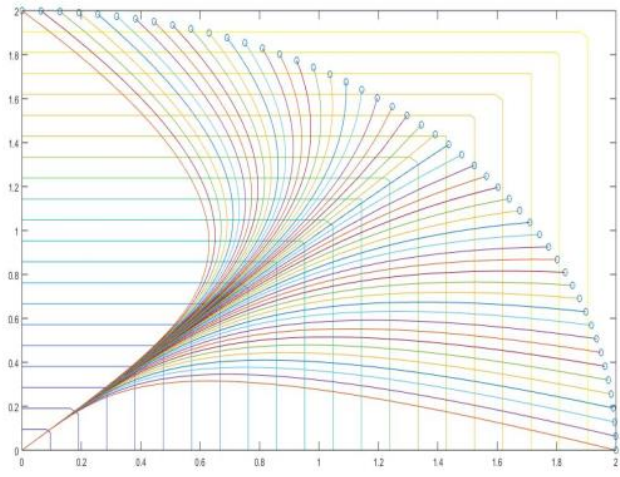

Figura 2. Função Máximo

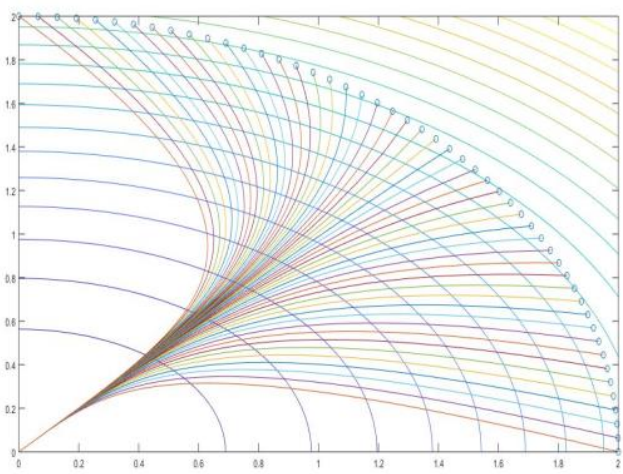

Figura 3. Função Quadrática

\section{Conclusões}

Ao analisarmos os resultados do desenvolvimento do projeto podemos verificar que dado qualquer valor inicial ao sistema positivo, suas trajetórias devem convergir a origem (ponto de equilíbrio), independentemente da função de Lyapunov utilizada.

Desta forma verificou-se que os resultados obtidos foram coerentes com a teoria de controle abordada durante a iniciação científica e desenvolvida no relatório final de atividades.

\section{Agradecimentos}

Agradeço imensamente ao Prof. Dr. Matheus Souza por todo o empenho em transferir seu conhecimento aos seus alunos e agradeço ao programa CNPq-PIBIC pelo financiamento da pesquisa.

${ }^{1}$ M.Souza, Networked Control of Dynamical Systems. 2015.

2 DG Luenberger,,Introduction to Dynamic Systems, 1973. 